«Системні технології» 4 (129) 2020 «System technologies»

DOI 10.34185/1562-9945-4-129-2020-14

УДК 681.3 .06

К.Ю. Островська

\title{
ДОСЛІДЖЕННЯ МЕТОДІВ ІНТЕЛЕКТУАЛЬНОГО АНАЛІЗУ ДАНИХ ДЛЯ ОБРОБКИ РЕЗУЛЬТАТІВ ТЕСТУВАННЯ
}

Анотація. Робота присвячена дослідженню методів інтелектуального аналізу даних для обробки результатів тестування з використанням мови Pуthon.

Метою даної роботи є дослідження методів інтелектуального аналізу даних засобами мови Python.

Для досягнення поставленої мети необхідно вирішення наступних завдань:

- дослідження етапів інтелектуального аналізу даних, особливостей підготовки і вивчення даних;

- дослідження задач інтелектуального аналізу даних і методів їх рішення;

- дослідження засобів мови Pуthon для вирішення завдань інтелектуального аналізу даHux;

- практичне рішення задач ІАД: побудова моделей інтелектуального аналізу даних засобами мови Pуthon;

- аналіз якості побудованих моделей.

у даній роботі був проведений інтелектуальний аналіз даних, отриманих з системи управління навчанням Moodle.

Ключові слова: інтелектуальний аналіз даних, кластеризації, прогнозування, система управління навчанням, Python.

Постановка задачі. Інтелектуальний аналіз даних або Data Mining $є$ однією 3 активно що розвиваються областей інформаційних технологій, призначеної для виявлення прихованих i нетривіальних знань 3 даних. Технології інтелектуального аналізу даних знаходять своє застосування в різних областях діяльності людини: наукові дослідження, охорону здоров'я, ділова галузь, фінансова сфера та багато інших.

Одним $з$ таких напрямків є сфера освіти. На даний момент слід відзначити існування таких спеціальних систем в сфері освіти, які називаються «Системи управління навчанням».

(C) Островська К.Ю., 2020 
«Системні технології» 4 (129) 2020 «System technologies»

Система управління навчанням (Learning Management System, LMS) - система для управління навчальною діяльністю, яка використовується для створення, управління і поширення навчальних матеріалів з забезпеченням доступу до інформації.

Система управління навчанням дозволяє:

- розміщувати навчальні матеріали, забезпечуючи доступ до них і розподіляючи навантаження;

- контролювати процес вивчення матеріалу і терміни виконання завдань;

- організовувати взаємодію учасників навчального процесу;

- відслідковувати різного роду статистику;

- формувати звітність, проводити документування навчального процесу; та ін.

Основні функції системи управління навчанням представлені на рисунку 1.

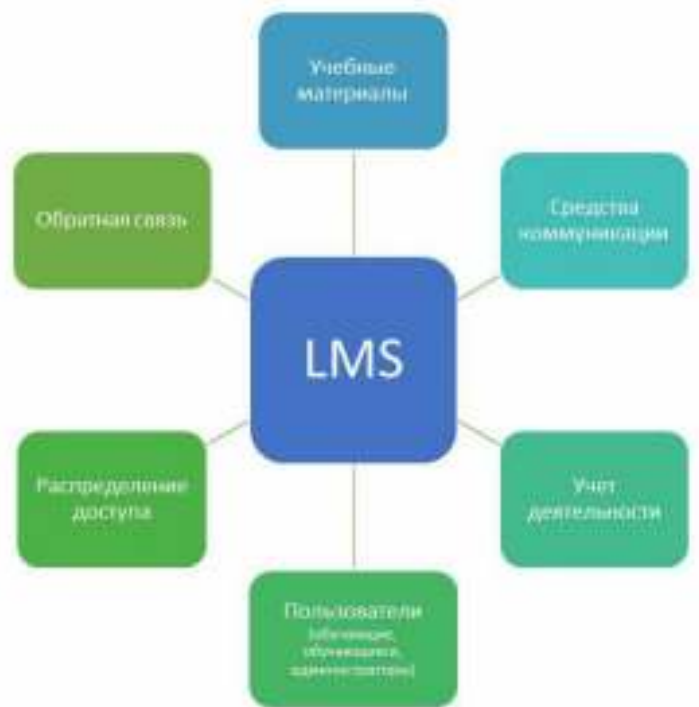

Рисунок 1 - Система управління навчанням

Прикладами систем управління навчання $є$ Moodle, OpenedX, Blackboard i iн. Така система здатна накопичувати величезний обсяг інформації про процес навчання, містити різного роду статистику про навчання: результати тестувань, швидкість виконання завдань і багато інших даних. Аналіз такої інформації може бути застосований з метою 
«Системні технології» 4 (129) 2020 «System technologies»

поліпшення освітнього процесу, розробки рекомендацій, як викладачеві, так і учневі.

У зв'язку з цим з'явилося такий напрямок як Educational Data Mining.

Educational Data Mining (EDM) - новий напрямок інтелектуального аналізу даних, засноване на зборі, аналізі та поданні даних, отриманих 3 освітніх параметрів, з метою оптимізації навчального процесу.

За допомогою впровадження EDM стає можливим рішення таких задач, як сегментація навчаються, прогнозування (передбачення результату навчання студента), генерація рекомендація зацікавленим особам (навчається, викладач, вищий навчальний заклад) і ін.

Система Moodle - система дистанційного навчання, орієнтована на організацію взаємодії між викладачем і студентом, при цьому система підходить як для організації дистанційних курсів, так і для організації процесу очного навчання.

Система Moodle надає можливість створювати курси, розміщуючи навчальні матеріали, а також забезпечує таку форму контролю знань як тестування.

При цьому система має спеціальними інструментами для створення тестів і проведення навчального і контрольного тестування.

Тестові завдання можуть бути різних типів: множинний вибір, питання на відповідність, з коротким відповіддю і багато інших.

Система проводить також і обробку даних тестів, вона містить в собі статистичні показники для оцінки результатів тестування, оцінки складності окремих тестових питань та ін.

Розглянемо деякі з даних показників.

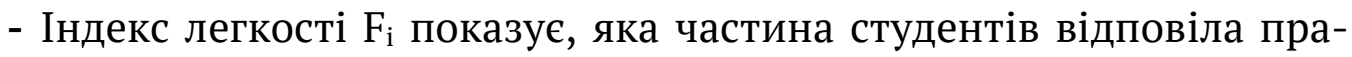
вильно на аналізовані питання.

$$
F_{i}=\frac{\overline{x_{i}}}{x_{i}(\max )}
$$

де $\overline{\mathrm{x}_{\mathrm{i}}}$ - середнє значення набраних студентами балів за $\mathrm{i}$ - е тестове завдання, $\mathrm{x}_{\mathrm{i}}(\max )$ - максимально можлива оцінка за $i$ е тестове завдання. 
«Системні технології» 4 (129) 2020 «System technologies»

Необхідно, щоб тест містив завдання різного рівня складності, але при цьому виключав завдання з індексом легкості рівним як 1, так і 0 (що означає, що завдання є надмірно простим або надмірно складним).

- Стандартне відхилення характеризує розкид значень оцінок, отриманих за дане завдання тесту. Стандартне відхилення дорівнює 0 означає, що всі студенти отримали за питання однакову оцінку.

- Бал випадкового вгадування - оцінка, яку міг би отримати студент при випадковому вгадуванні відповідей. Наприклад, якщо необхідно вибрати один варіант з чотирьох, то бал випадкового вгадування становитиме $25 \%$.

- Намічена вага - вага, якій призначається тестове завдання при формуванні сценарію тесту.

$$
I Q W_{p}=100 \% \cdot \frac{x_{p}(\max )-x_{p}(\min )}{T_{\max }-T_{\min }},
$$

де $\mathrm{x}_{\mathrm{p}}(\max ), \mathrm{x}_{\mathrm{p}}(\min )$ - максимально i мінімально можливі оцінки за завдання, $\mathrm{T}_{\max }, \mathrm{T}_{\min }$ - максимальна і мінімальна можливі оцінки за тест. $\mathrm{T}_{\min }$ завжди рівні 0.

Параметр розраховується для «позиції» завдання в тесті, тобто на кожну позицію випадково вибирається один 3 декількох альтернативних питань на задану тему.

Прийняті позначення:

- I - множена питань;

- P - множена позицій в тесті;

- $S$ - множена спроб здачі тесту;

- $T_{s}$ - кількість набраних балів за тест;

- $x_{p}(s)$ - оцінка студента за конкретне завдання;

- $X_{p}(s)$ - оцінка студента за всі інші завдання.

$$
\begin{aligned}
& T_{s}=\sum_{p \in P} x_{p}(s), \\
& X_{p}(s)=T_{s}-x_{p}(S) .
\end{aligned}
$$

Дисперсія показника: 
«Системні технології» 4 (129) 2020 «System technologies»

$$
V\left(x_{p}\right)=\frac{1}{S-1} \sum_{s \in S}\left(x_{p}(s)-\bar{x}_{p}\right)^{2} .
$$

Коваріація:

$$
C\left(x_{p}, X_{p}\right)=\frac{1}{S-1} \sum_{s \in S}\left(x_{p}(s)-\bar{x}_{p}\right)\left(X_{p}(s)-\bar{X}_{p}\right)^{2} .
$$

- Ефективна вага характеризує фактичну частку конкретного завдання в підсумковій оцінці студентів за тест:

$$
E Q W_{p}=100 \% \cdot \frac{\sqrt{C\left(x_{p}, T\right)}}{\sum_{p \in P} \sqrt{C\left(x_{p}, T\right)}} .
$$

- Індекс дискримінації показує, наскільки взаємопов'язані правильність відповіді на дане питання і інші питання тесту:

$$
D_{p}=100 \% \cdot \frac{C\left(x_{p}, X_{p}\right)}{\sqrt{V\left(x_{p}\right) V\left(X_{p}\right)}} .
$$

Для хорошого тестового питання студенти з високими оцінками за нього також матимуть високі оцінки за тест в цілому, на що вкаже позитивне значення коефіцієнта. Якщо індекс легкості питання різниться від $50 \%, D_{p}$ не може бути $100 \%$. Якщо індекс легкості близький до $0 \%$ або $100 \%$, то $D_{p}$ буде малий, а за однакової кількості індексу легкості $0 \%$ або $100 \% D_{p}$ буде не визначений.

- Ефективність дискримінації враховує зазначену вище особливість:

$$
D E_{p}=100 \% \cdot \frac{C\left(x_{p}, X_{p}\right)}{C_{\max }\left(x_{p}, X_{p}\right)},
$$

де $\mathrm{C}\left(\mathrm{x}_{\mathrm{p}}, \mathrm{X}_{\mathrm{p}}\right)$ розраховується за формулою (6), для розрахунку $\mathrm{C}_{\max }\left(\mathrm{x}_{\mathrm{p}}, \mathrm{X}_{\mathrm{p}}\right)$ множени значень $\mathrm{X}_{\mathrm{p}}(\mathrm{s})$ та $\mathrm{X}_{\mathrm{p}}(\mathrm{s})$ попередньо сортуються за зростанням.

Система дистанційного навчання Moodle використовується для організації процесу навчання.

У 2018/2019 навчальному році на кафедрі «ITC» дисципліна « Прикладні нейро-нечіткі системи» викладалася студентам 4-го курсу на російській мові. 
«Системні технології» 4 (129) 2020 «System technologies»

Проміжне і підсумкове тестування проводилися за допомогою середовища дистанційного навчання Moodle. Студенти кафедри проходили три проміжних тесту.

Екзаменаційний тест проводився російською мовою.

За допомогою методів інтелектуального аналізу даних в даній роботі необхідно провести аналіз якості завдань: оцінити складність питань, виявити схожі за рівнем складності питання в тесті, визначити співвідношення результатів тестів.

У даній роботі необхідно провести рішення наступної задачі:

Необхідно провести кластеризацію тестових завдань для аналізу їх складності, виявлення схожих за рівнем складності питань в тесті. Таким чином, множена тестових завдань:

$$
Q=\left\{q_{1}, q_{2}, \ldots, q_{j}, \ldots, q_{n}\right\},
$$

де $q_{j}$ - тестове завдання.

Необхідно розділити досліджувану множену тестових завдань на кластери, то є побудувати дискретну множену кластерів $C$ :

$$
C=\left\{c_{1}, c_{2}, \ldots, c_{k}, \ldots, c_{g}\right\}
$$

і відображення $F$ множени $Q$ на множену $C(F: Q \rightarrow C)$.

Рішення даного завдання дозволить оцінити якість тестових завдань, складність питань, а також виявити схожі за рівнем складності завдання.

У даній роботі необхідно знайти рішення задач інтелектуального аналізу даних засобами мови Рython.

Досліджуваний набір даних. Задача кластеризації тестових завдань. Необхідно провести кластеризацію тестових завдань:

$\mathrm{Q}=\left\{\mathrm{q}_{1}, \mathrm{q}_{2}, \ldots \mathrm{q}_{\mathrm{j}} \ldots, \mathrm{q}_{\mathrm{n}}\right\}$, де $\mathrm{q}_{\mathrm{j}}$ - тестове завдання.

Задача полягає в побудові дискретної множени кластерів $\mathrm{C}$ : $\mathrm{C}=$ $\left\{\mathrm{c}_{1}, \mathrm{c}_{2}, \ldots \mathrm{c}_{\mathrm{k}} \ldots, \mathrm{c}_{\mathrm{g}}\right\}$.

Досліджуваним набором даних в даній задачі є статистичні показники тестувань, що надаються системою Moodle, приклад яких представлений на рисунку 2. 
«Системні технологіï» 4 (129) 2020 «System technologies»

\begin{tabular}{|c|c|c|c|c|}
\hline 1 & Tun sonpoca & Haseaume nonpoca & Мrapenc nerkocti & Стаидартиое огипонеми \\
\hline 2 & 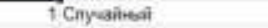 & 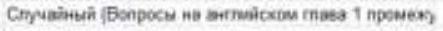 & $456444 \%$ & $48.81 \%$ \\
\hline 3. & 2 Cny-aî́baî & 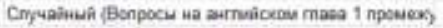 & $45.51 .11 \mathrm{~s}$ & $5055 \mathbf{s}$ \\
\hline 4 & 9. Cmyvaìneal & 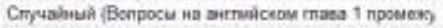 & $45.05 .00 \%$ & $49.54 \%$ \\
\hline 3 & 4 Crycaînesaî & 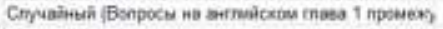 & $456000 \%$ & $49.54 \%$ \\
\hline 5 & 5 Cny-aînail & 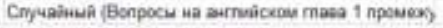 & $45.48 .29 \%$ & $50.55 \%$ \\
\hline 7 & 8 Conyeahieal & 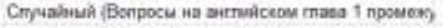 & $45.46 .67 \%$ & $50.45 \%$ \\
\hline \& & 7 Cпучаäreal & 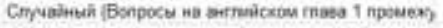 & $45.62 .22 \%$ & $4903 \%$ \\
\hline 9 & 7,1 Muanscresumai aubop & q060 A Customer Resource Managemant (CRM) gysten & $2119.05 \mathrm{~s}$ & $40.24 \%$ \\
\hline 10 & 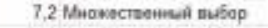 & q063 A program whose jab is to creario, procens and ad & $1687.50 \%$ & $34,66 \%$ \\
\hline II & 7.3 Mnakecreentoil вы5op & 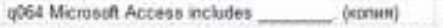 & $16.68 .75 \%$ & $47.87 \%$ \\
\hline 12 & 7,4 Mhowscresumaí aubop & Q068 Which of the following daxibase systems is noterf & $1457,14 \mathrm{~S}$ & $5136 \%$ \\
\hline 13 & 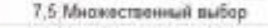 & Q071 b databuse syatems, the DBMS enforcee niee at & 1325085 & $43.65 \%$ \\
\hline 14 & 7.6 Phanecreenesil bofop & q073 A datatase is considered set-descritingtecause. & $1283,33 \%$ & $33.92 \%$ \\
\hline 15 & 7,7 Muevecresumaí ausop & q075 Which of the bilowing stakemants is nottrue far pri & $184444 \mathrm{~s}$ & $51.13 \%$ \\
\hline in & 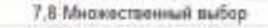 & Q070 A databose designod utiog aprosadshests from the & $1002.00 \%$ & $42.16 \%$ \\
\hline 17 & 7,9 Mnakecreeunsal bu5op & प063 A very popular developmemt tectrique used by dat & $1856.56 \mathrm{~N}$ & $69.13 \%$ \\
\hline 19 & 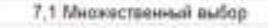 & 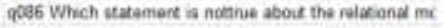 & $16.25 .00 \mathrm{~N}$ & $44 \mathrm{TZW}$ \\
\hline 29 & 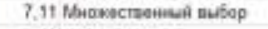 & 4090 for datatase developmere, a chalenge to the reial & $1711.76 \%$ & $30.21 \%$ \\
\hline 20 & 7,12 BepmaiHesepno & Y002 ls a daratase, each tatie stares data about a difte & $1770.59 \%$ & $46.97 \%$ \\
\hline 21 & 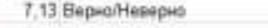 & q006 Dasa is recorded tacts and figues, infamation is $k$ & $16100.00 \%$ & $0.00 \mathrm{~N}$ \\
\hline 22 & 7. 14 Elopenitiesepus & Q014 Databases based on the COCASYL standart are I & $1656.25 \%$ & $5123 \%$ \\
\hline 20 & 7.15 Bepmoil Hesepno & q002 h an Enterprise ciass datatase system, business & $144236 \%$ & $61.36 \%$ \\
\hline 24 & 7,16 Вер-ой Неворев & po39 The descripeon of a daciabase's structive bat is st & $196942 \%$ & $47,76 \%$ \\
\hline 39 & 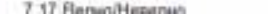 & 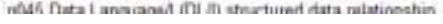 & $15 \mathrm{mons}$ & A1 $2 \mathrm{ht}$ \\
\hline
\end{tabular}

Рисунок 2 - Статистичні показники тестування

Аналіз даних засобами мови Python. Дані являють собою кількісні ознаки (тип даних int, float).

Проміжне тестування №1.

Метод describe () дозволяє отримати зведену інформацію 3 даної таблиці (рисунок 3).

\begin{tabular}{|c|c|c|c|c|c|c|c|}
\hline & $\mathbf{F}$ & SaDev & RGS & Iow & EQW & D & DE \\
\hline unt & 55.000000 & 55.000000 & 55.000000 & $5.5000000+01$ & 55,000000 & 55.000000 & 55.000000 \\
\hline mean & 54156636 & 45.534909 & 23 181a18 & $6.670000 e+\infty 0$ & 1. & 23.637455 & 33.522182 \\
\hline std & 20.560735 & 6708393 & 17.249996 & 8. $9636469-16$ & 3.080082 & 25.212404 & 35.565313 \\
\hline $\min$ & 11.760000 & 24250000 & 0.000000 & $6.670000 e+00$ & 0.000000 & 41.670000 & 59120000 \\
\hline $25 \%$ & 51.060000 & $\$ 2765000$ & 0,000000 & $6.6700000+\infty 0$ & 0.000000 & 5.075000 & 6.800000 \\
\hline $50 \%$ & 61.110000 & 48.570000 & 25.000000 & $6.670000 \theta+\infty 0$ & 0,000000 & 21.280000 & 31.360000 \\
\hline $75 \%$ & 69.375000 & 50.160000 & 25.000000 & $6.670000 \mathrm{e}+00$ & 4.130000 & 44.140000 & 68.515000 \\
\hline $\max$ & 94.120000 & 51.450000 & 50.000000 & $6.6700000+\infty 00$ & 8.800000 & 81.720000 & 100.000000 \\
\hline
\end{tabular}

Рисунок 3 - Характеристика досліджуваного набору даних

Для оцінки досліджуваного числа кластерів була побудована дендрограмма (рисунок 4) і залежність функції $\mathrm{J}(\mathrm{k})$ від кількості кластерів (рисунок 5). Вибір кількості кластерів відбувається на підставі найменшого зміни функції. 
«Системні технології» 4 (129) 2020 «System technologies»

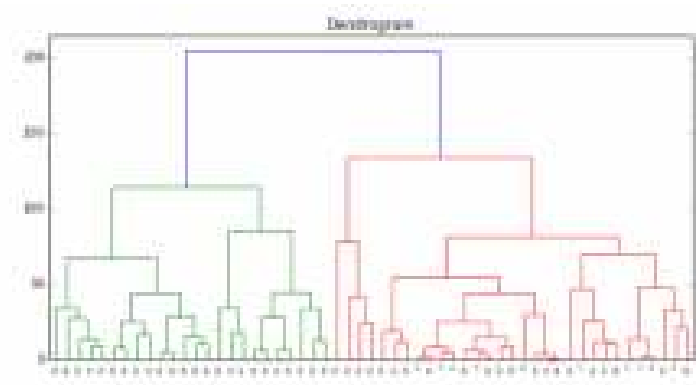

Рисунок 4 - Дендрограмма

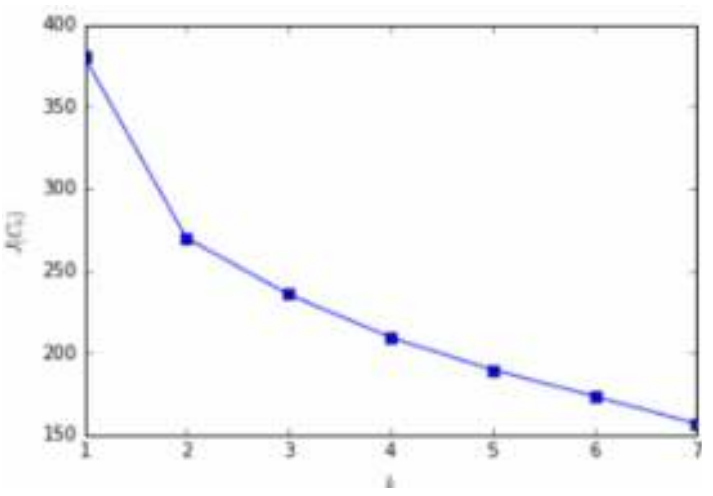

Рисунок 5 - Залежність функції $\mathrm{J}(\mathrm{k})$ від кількості кластерів

Були побудовані моделі Інтелектуального Аналізу Даних, що містять 2, 3, 4 і 5 кластерів.

Для перевірки точності моделі був застосований інструмент перехресної перевірки (рисунок 6 - 9).

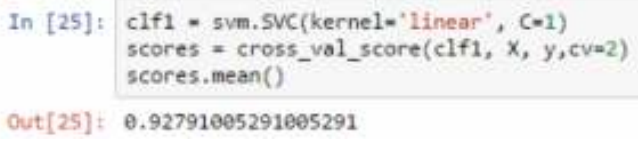

Рисунок 6 - Перехресна перевірка моделі (2 кластера)

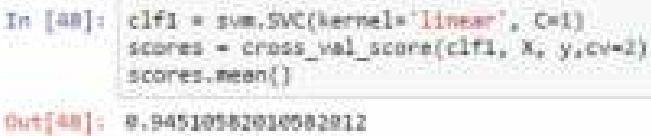

\section{Рисунок 7 - Перехресна}

перевірка моделі (3 кластера)

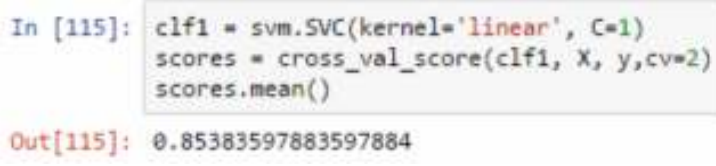

Out[115]: $\quad 0.85383597883597884$

Рисунок 8 - Перехресна перевірка моделі (4 кластера)

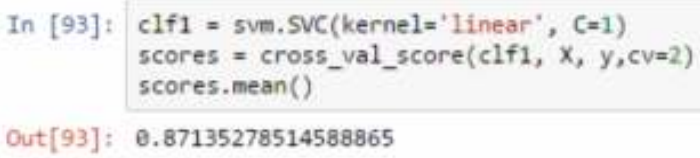

Рисунок 8 - Перехресна перевірка моделі (5 кластерів)

Модель ІАД, що містить 3 кластера, забезпечує найбільш точний результат.

Результати кластеризації тестового набору даних в 95\% випадків збігаються з результатами кластеризації вихідних даних.

В результаті роботи алгоритму кластеризації були отримані 3 кластера.

Перший кластер містить 16 об'єктів, другий - 22 об'єкти, третій 17 (рисунок 9). 
«Системні технології» 4 (129) 2020 «System technologies»

\section{Соотношение количества объектов}

в кластерах

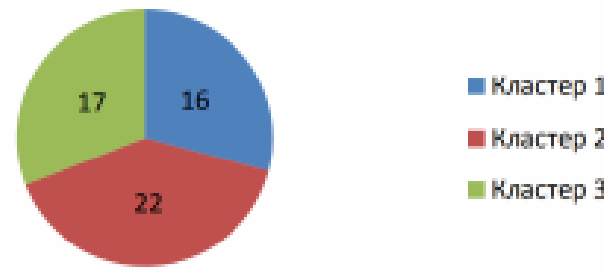

Рисунок 9 - Співвідношення кількості об'єктів в кластерах

На підставі результатів кластеризації були складені таблиці, що містять що належать певному кластеру об'єкти (рисунки 10 - 12).

\begin{tabular}{|l|l|l|l|l|l|l|l|l|l|}
\hline & ID & F & StDev & RGS & IOW & EOW & D & DE & Cluster \\
\hline 0 & 1 & 57.45 & 49.98 & 0.0 & 6.67 & 6.18 & 3.58 & 4.84 & 1 \\
\hline 1 & 2 & 53.19 & 50.44 & 0.0 & 6.67 & 4.09 & -10.99 & -14.57 & 1 \\
\hline 2 & 3 & 63.83 & 48.57 & 0.0 & 6.67 & 5.87 & 2.35 & 3.15 & 1 \\
\hline 3 & 5 & 51.06 & 50.53 & 0.0 & 6.67 & 5.51 & -2.16 & -2.90 & 1 \\
\hline 4 & 6 & 55.32 & 50.25 & 0.0 & 6.67 & 4.17 & -10.44 & -14.02 & 1 \\
\hline 5 & 7 & 61.70 & 49.14 & 0.0 & 6.67 & 6.28 & 5.35 & 6.93 & 1 \\
\hline 6 & 8 & 21.05 & 41.89 & 25.0 & 6.67 & 0.00 & -3.26 & -391 & 1 \\
\hline 7 & 10 & 68.75 & 47.87 & 25.0 & 6.67 & 0.00 & -3.87 & -5.05 & 1 \\
\hline 5 & 16 & 68.75 & 47.87 & 25.0 & 6.67 & 0.00 & -41.67 & -59.12 & 1 \\
\hline 9 & 24 & 75.00 & 44.72 & 50.0 & 6.67 & 0.00 & -12.38 & -16.67 & 1 \\
\hline 10 & 27 & 61.11 & 50.16 & 25.0 & 6.67 & 0.00 & 8.22 & 10.64 & 1 \\
\hline 11 & 31 & 55.32 & 50.25 & 0.0 & 6.67 & 6.12 & 2.85 & 3.72 & 1 \\
\hline 12 & 38 & 86.36 & 35.13 & 25.0 & 6.67 & 0.00 & -0.88 & -1.54 & 1 \\
\hline 13 & 49 & 23.81 & 43.64 & 25.0 & 6.67 & 0.00 & 4.80 & 6.67 & 1 \\
\hline 14 & 53 & 92.86 & 26.73 & 50.0 & 6.67 & 0.00 & -18.26 & -37.70 & 1 \\
\hline 15 & 54 & 86.67 & 35.19 & 50.0 & 6.67 & 0.00 & -0.77 & -1.35 & 1 \\
\hline
\end{tabular}

Рисунок 10 - Об'єкти

першого кластера

\begin{tabular}{|c|c|c|c|c|c|c|c|c|c|}
\hline & 10 & F & Scodev & RGS & Iow & EOW & D & DE & Clusber \\
\hline 0 & 4 & 65.96 & 47.90 & 0.0 & 6.67 & 7.23 & 16.11 & 22.19 & 2 \\
\hline 1 & 9 & 78.95 & 4189 & 25.0 & 6.67 & 000 & 1463 & 21.92 & 2 \\
\hline 2 & 11 & 55.56 & 5113 & 250 & 5.67 & 0.00 & 2294 & 31.36 & 2 \\
\hline 3 & 12 & 2500 & 4523 & 250 & 6.67 & 000 & 3397 & 50.00 & 3 \\
\hline 4 & 13 & 65.71 & 36.31 & 25.0 & 6.67 & 0.00 & 25.07 & 33.33 & 2 \\
\hline 5 & 14 & 52.94 & 51.45 & 250 & 6.67 & 0.00 & 21.12 & 29.53 & 2 \\
\hline 6 & 15 & 05.71 & 35.31 & 250 & 667 & 0.00 & 2519 & 47.50 & 2 \\
\hline 7 & 18 & 18.75 & 40.31 & 250 & 5.67 & 0.00 & 9.29 & 1409 & 2 \\
\hline 3 & 20 & 94,12 & 2425 & 50.0 & 6.67 & 0.00 & 13,30 & 40.35 & 2 \\
\hline 9 & 25 & 41.18 & 50.73 & 50.0 & 6.67 & 0.00 & 16.25 & 22.73 & 2 \\
\hline 10 & 26 & 81.25 & 40.31 & 25.0 & 6.67 & 0.00 & 26.45 & 40,74 & 2 \\
\hline 11 & 28 & 63.83 & 4357 & 0.0 & 6.57 & 880 & 3478 & 4732 & 2 \\
\hline 12 & 29 & 59.57 & 49.61 & 0.0 & 5.67 & 7.48 & 1671 & 21.54 & 2 \\
\hline 13 & 30 & 55.32 & 50.25 & 00 & 6.87 & 8.64 & 29.88 & 39.67 & 2 \\
\hline 14 & 32 & 55.32 & 5025 & 0.0 & 6.67 & 6.98 & 10.82 & 14.21 & 2 \\
\hline 15 & 33 & 63.83 & 48.57 & 0.0 & 5.67 & 7.18 & $14 \pi$ & 19.29 & 2 \\
\hline 16 & 34 & 63.03 & 43.57 & 0.0 & 6.67 & 7.94 & 23.44 & 31.76 & 2 \\
\hline 17 & 35 & 51.06 & 50.53 & 00 & 6.67 & 7.50 & 15.67 & 2079 & 2 \\
\hline 18 & 41 & 92.31 & 27.17 & 250 & 667 & 000 & 2944 & 5806 & 2 \\
\hline 19 & 42 & 23.00 & 45.83 & 25.0 & 6.67 & 0.00 & 11.48 & 16.73 & 2 \\
\hline 20 & 40 & 31.25 & 47.87 & 250 & 6.67 & 0.00 & 25.57 & 35.14 & 2 \\
\hline 21 & 50 & 52.63 & 5130 & 25.0 & 6.67 & 0,00 & 21.28 & 29.89 & 17 \\
\hline
\end{tabular}

Рисунок 11 - Об'єкти

другого кластера 
«Системні технології» 4 (129) 2020 «System technologies»

\begin{tabular}{|l|l|l|l|l|l|l|l|l|l|}
\hline & ID & F & StDev & RGS & IQW & EQW & D & DE & Cluster \\
\hline 0 & 17 & 33.33 & 48.80 & 25.0 & 6.67 & 0.0 & 56.85 & 81.25 & 3 \\
\hline 1 & 19 & 62.50 & 50.00 & 50.0 & 6.67 & 0.0 & 44.78 & 58.97 & 3 \\
\hline 2 & 21 & 55.00 & 51.04 & 50.0 & 6.67 & 0.0 & 43.50 & 55.56 & 3 \\
\hline 3 & 22 & 37.50 & 50.00 & 50.0 & 6.67 & 0.0 & 58.30 & 87.10 & 3 \\
\hline 4 & 23 & 64.71 & 49.26 & 50.0 & 6.67 & 0.0 & 57.61 & 74.05 & 3 \\
\hline 5 & 36 & 60.00 & 50.71 & 25.0 & 6.67 & 0.0 & 67.59 & 87.95 & 3 \\
\hline 6 & 37 & 78.95 & 41.89 & 25.0 & 6.67 & 0.0 & 54.29 & 78.57 & 3 \\
\hline 7 & 39 & 81.82 & 39.48 & 25.0 & 6.67 & 0.0 & 45.19 & 72.27 & 3 \\
\hline 8 & 40 & 64.71 & 49.26 & 25.0 & 6.67 & 0.0 & 68.73 & 100.00 & 3 \\
\hline 9 & 43 & 11.76 & 33.21 & 25.0 & 6.67 & 0.0 & 39.65 & 55.84 & 3 \\
\hline 10 & 44 & 70.00 & 47.02 & 25.0 & 6.67 & 00 & 52.97 & 73.51 & 3 \\
\hline 11 & 45 & 33.33 & 49.24 & 25.0 & 6.67 & 0.0 & 81.72 & 100.00 & 3 \\
\hline 12 & 46 & 64.71 & 49.26 & 25.0 & 6.67 & 0.0 & 42.20 & 56.78 & 3 \\
\hline 13 & 47 & 61.11 & 50.16 & 25.0 & 6.67 & 0.0 & 45.30 & 59.40 & 3 \\
\hline 14 & 51 & 28.57 & 46.29 & 25.0 & 6.67 & 0.0 & 56.66 & 76.86 & 3 \\
\hline 15 & 52 & 75.00 & 44.23 & 50.0 & 6.67 & 0.0 & 45.99 & 69.23 & 3 \\
\hline 16 & 55 & 31.25 & 47.87 & 50.0 & 6.67 & 0.0 & 58.10 & 90.12 & 3 \\
\hline
\end{tabular}

\section{Рисунок 12 - Об'єкти}

\section{третього кластера}

\section{Для оцінки основних характеристик кластерів був застосований} метод describe() (рисунки 13-15).

\begin{tabular}{|c|c|c|c|c|c|c|c|}
\hline & F & StDev & RGS & iow & EOW & D & $D E$ \\
\hline coant & 16.000000 & 16000000 & 16.000000 & $1.600000 \mathrm{e}+1 \mathrm{dT}$ & 16.000000 & 16.000000 & 1660000 \\
\hline mean & 61 3agat5 & 45.147500 & 18.750000 & $589700000+00$ & 2.388750 & 4345625 & -755500 \\
\hline st & 15.757436 & 7 073462 & 15354917 & $2173067+16$ & 2860317 & 12.259695 & 1825059 \\
\hline min & 21.050000 & 267330000 & 0,000000 & $66570000=\div 00$ & 0,000000 & 41.670000 & .5912000 \\
\hline $25 \%$ & 54.787500 & 43.202500 & 0.000000 & $6.670060 \mathrm{e}+00$ & 0,000000 & .10577500 & t14 15750 \\
\hline $50 \%$ & 61.05000 & 48.220000 & 25.0000000 & $6670000 v=00$ & 0.000000 & -1520000 & -2.22000 \\
\hline $75 \%$ & 70312500 & 50.182500 & 25.000000 & $6.570000=000$ & 5600000 & 3002560 & 400000 \\
\hline $\max$ & 82.860000 & 50.530000 & 60,000000 & $6.670000 \mathrm{e} \cdot 00$ & 6.290000 & 8220000 & 1064000 \\
\hline
\end{tabular}

Рисунок 13 - Характеристики

першого кластера

\begin{tabular}{|c|c|c|c|c|c|c|c|}
\hline & $\mathrm{F}$ & Sthey & Rags & IOW & EOW & D & DE. \\
\hline count & 22000000 & 22.000000 & 22.000500 & $2.2000000=01$ & 22000000 & 22000000 & 22000000 \\
\hline meen & 59.185456 & 44.742727 & 18. 181818 & e. $670000 \mathrm{e} \cdot 00$ & 2807273 & 20.825455 & $3+.233636$ \\
\hline stu & 21505732 & 7.752374 & 15777127 & $5,090796 \div-15$ & 3821245 & 7,449512 & 12480286 \\
\hline $\min$ & \$8 750000 & 24.250000 & 0,000000 & $6.670000 \mathrm{e}+00$ & 0.000000 & 9.290000 & 14.050000 \\
\hline $25 \%$ & 51.462500 & 40.705000 & 0000000 & $5,6200000+00$ & 0,000000 & 14995000 & 21.635000 \\
\hline $\sin$ & $5 \pi 565000$ & 48 235000 & 25000000 & $5670000+00$ & 0000000 & 21200000 & 30626000 \\
\hline $75 \%$ & 75.702500 & 60.250000 & 25.000000 & $6.570000 \mathrm{e}+00$ & 7.217500 & 25.476000 & $40+160000$ \\
\hline$a x$ & 94120000 & 51.450000 & 50000000 & f. $6700000+00$ & 18000000 & 34.720000 & SA Desco. \\
\hline
\end{tabular}

Рисунок 14- Характеристики другого кластера

\begin{tabular}{|l|l|l|l|l|l|l|l|}
\hline & F & StDev & RGS & IQW & EQW & D & DE \\
\hline count & 17.000000 & 17.000000 & 17.000000 & 1.700000 e+01 & 17.0 & 17.000000 & 17.000000 \\
\hline mean & 53.779412 & 46.924706 & 33.823529 & 6.670000 e+00 & 0.0 & 54.084118 & 75.144706 \\
\hline std & 20.420203 & 4.765214 & 12.314805 & $9.1551349-16$ & 0.0 & 11.159961 & 14.724161 \\
\hline min & 11.760000 & 33.210000 & 25.000000 & 6.670000 e+00 & 0.0 & 39.650000 & 55.560000 \\
\hline $25 \%$ & 33.390000 & 46.290000 & 25.000000 & 6.670000 e+00 & 0.0 & 45.190000 & 59.400000 \\
\hline S0\% & 61.110000 & 49.240000 & 25.000000 & $6.670000 e+00$ & 0.0 & 54.290000 & 74.050000 \\
\hline $75 \%$ & 64.710000 & 50.000000 & 50.000000 & $6.670000 e+00$ & 0.0 & 58.100000 & 87.100000 \\
\hline $\max$ & 81.820000 & 51.040000 & 50.000000 & $6.670000 e+00$ & 0.0 & 81.720000 & 100.000000 \\
\hline
\end{tabular}

\section{Рисунок 15 - Характеристики третього кластера}

Розглянемо основні характеристики кластерів. Значення індексу легкості кластерів: 
«Системні технології» 4 (129) 2020 «System technologies»

$F_{1} \in[21.05,92.86]$,

$F_{2} \in[18.75,94.12]$,

$F_{3} \in[11.76,81.82]$.

Значення стандартного відхилення кластерів:

$S t D e v_{1} \in[26.73,50.53]$,

$S t D e v_{2} \in[24.25,51.45]$,

$S t \operatorname{Dev}_{3} \in[33.21,51.04]$.

Значення індексу дискримінації кластерів:

$D_{p 1} \in[-41.67,8.22]$,

$D_{p 2} \in[9.29,34.78]$,

$D_{p 3} \in[39.65,81.72]$.

Значення індексу легкості і значення стандартного відхилення кластерів мають схожі значення. Основна відмінність кластерів укладає в значенні індексу дискримінації. Перший кластер включає в себе об'єкти 3 від'ємним значенням індексу дискримінації, що вказує на відсутність взаємозв'язку правильності відповіді на дані тестові питання з іншими відповідями на питання тестування. Даний кластер містить 16 тестових завдань, наприклад, питання №1, що відноситься до типу «випадковий», і питання №7.17, що відноситься до типу «вірно / невірно». другий кластер містить об'єкти з невеликим значенням індексу дискримінації $D p \in$ [9.29,34.78] В літературі відзначається, якщо індекс легкості близький до 0\% або 100\%, то індекс дискримінації буде малий. Третій кластер містить об'єкти з середнім значенням індексу дискримінації.

Таке дослідження було проведено і для проміжного тестування №2 та екзаменаційного тестування.

Рішення завдання засобами Руthon дозволило проаналізувати тестові завдання, характеризуються відсутністю взаємозв'язку правильності відповіді з іншими відповідями на питання тестування. 
«Системні технології» 4 (129) 2020 «System technologies»

Висновки. В ході написання даної роботи було проведено дослідження методів інтелектуального аналізу даних засобами мови Python.

В роботі були вивчені завдання інтелектуального аналізу даних, методи їх вирішення, а також кошти мови Руthon для вирішення цих завдань.

В якості досліджуваного набору даних були обрані результати тестування студентів кафедри «ІТС» за 2018/2019 рік по курсу «Прикладні нейро-нечіткі системи». Студенти проходили 2 проміжних тесту і один екзаменаційний тест в системі дистанційного навчання Moodle.

У даній роботі була поставлена і вирішена задача кластеризації тестових завдань. Дана задача була вирішена засобами мови Python, проте результати кластеризації не співпали. Рішення завдання засобами Python дозволило проаналізувати тестові завдання, які характеризуються відсутністю взаємозв'язку правильності відповіді з іншими відповідями на питання тестування, а також виявити співвідношення таких тестових завдань для тестувань, що проводяться.

\section{ЛІТЕРАТУРА / ЛИТЕРАТУРА}

1. Барсегян А.А. Технологии анализа данных: Data Mining, Visual Mining, Text Mining, OLAP. Учебное пособие. / A.A. Барсегян, М.С. Куприянов, В.В. Степаненко, И.И. Холод. - М.:БХВ-Петербург, 2007. - 331 с.

2. Нестеров С.А. Базы данных. Интеллектуальный анализ данных. Учебное пособие. / С.А. Нестеров. - СПБ.: Изд-во Политехн. ун-та, 2011. -272 с. 3. Чубукова И.A. Data Mining. Задачи Data Mining. Классификация и кластеризация. Режим доступа:

http://www.intuit.ru/studies/courses/6/6/lecture/166?page=4.

4. Структуры интеллектуального анализа данных (службы Analysis Services - интеллектуальный анализ данных). Режим доступа: https://msdn.microsoft.com/ru-ru/library/ms174757.

5. Путівник мовою програмування Python. Режим доступа: https://pythonguide.rozh2sch.org.ua/

\section{REFERENCES}

1. Barsegyan A.A. Tehnologii analiza dannyih: Data Mining, Visual Mining, Text Mining, OLAP. Uchebnoe posobie. / A.A. Barsegyan, M.S. Kupriyanov, V.V. Stepanenko, I.I. Holod. - M.:BHV-Peterburg, 2007. - 331 s. 
«Системні технології» 4 (129) 2020 «System technologies»

2. Nesterov S.A. Bazyi dannyih. Intellektualnyiy analiz dannyih. Uchebnoe posobie. / S.A. Nesterov. - SPB.: Izd-vo Politehn. un-ta, 2011. -272 s.

3. Chubukova I.A. Data Mining. Zadachi Data Mining. Klassifikatsiya i klasterizatsiya. Rezhim dostupa:

http://www.intuit.ru/studies/courses/6/6/lecture/166?page=4.

4. Strukturyi intellektualnogo analiza dannyih (sluzhbyi Analysis Services intellektualnyiy analiz dannyih). Rezhim dostupa:

https://msdn.microsoft.com/ru-ru/library/ms174757.

5. PutIvnik movoyu programuvannya Python. Rezhim dostupa: https://pythonguide.rozh2sch.org.ua/

Received 12.03.2020. Accepted 16.03.2020

Исследование методов интеллектуального анализа даннях для обработки результатов тестирования

Работа посвящена исследованию методов интеллектуального анализа данных для обработки результатов тестирования с использованием языка Python.

Целью данной работы является исследование методов интеллектуального анализа данных средствами языка Pуthon.

Для достижения поставленной цели необходимо решение следующих задач:

- исследование этапов интеллектуального анализа данных, особенностей подготовки и изучения данных;

- исследование задач интеллектуального анализа данных и методов их решения;

- исследование средств языка Pуthon для решения задач интеллектуального анализа данных;

- практичное решение задач ИАД: построение моделей интеллектуального анализа данных средствами языка Pуthon;

- анализ качества построенных моделей.

В данной работе был проведен интеллектуальный анализ данных, полученных из системы управления обучением Moodle.

Research methods of data mining for processing test results

The work is devoted to the study of data mining methods for processing test results using the Python language.

The aim of this work is to study methods of data mining using Python.

To achieve this goal it is necessary to solve the following tasks:

- study of the stages of data mining, features of the preparation and study of data;

- study of data mining problems and methods for solving them;

- research of Python language tools for solving data mining problems;

- a practical solution to the problems of IAD: building data mining models using Python;

- analysis of the quality of the constructed models.

In this work, an intellectual analysis of the data obtained from the Moodle learning management system was carried out.

In the work, data mining problems, methods for solving them, and also Python tools for solving these problems were studied. 
«Системні технології» 4 (129) 2020 «System technologies»

As the studied data set, the results of testing students of the ITS department for 2018/2019 at the course "Applied Neuro-Fuzzy Systems" were selected. Students took 2 intermediate tests and one exam test in the Moodle distance learning system.

In this paper, the task of clustering test tasks was posed and solved. This task was solved using the Python language, but the clustering results did not match. Solving the problem using Python tools allowed us to analyze test tasks, which are characterized by the absence of a correlation between the correctness of the answer and other answers to testing questions, and also to identify the relationship of such test tasks for testing conducted.

Островская Екатерина Юрьевна - к.т.н., доцент кафедри информационных технологыий и систе, Нациаональныя металлургическая академия Украины.

Островська Катерина Юріївна - к.т.н., доцент кафедри Інформаційних технологій та систем, Національна металургійна академія України.

Ostrovska Kateryna - candidate of technical sciences, associate professor of the Department of Information Technology and System, National Metallurgical Academy of Ukraine. 